\title{
Simulação da Dinâmica de Nutrientes no Trato Gastrintestinal: Aplicação e Validação de um Modelo Matemático para Bovinos a Pasto 1
}

\section{Ricardo Augusto Mendonça Vieira², José Carlos Pereira ${ }^{3}$, Pedro Antônio Muniz Malafaia ${ }^{4}$, Augusto Cesar de Queiroz ${ }^{3}$, Cláudio P. Jordão ${ }^{5}$, André Luigi Gonçalves ${ }^{6}$}

\begin{abstract}
RESUMO - O objetivo do presente trabalho foi a validação das predições da dinâmica ruminal e pós-ruminal dos nutrientes e do crescimento microbiano no rúmen, usando as equações do sistema Cornell. O experimento foi realizado durante as estações chuvosa e seca do ano de 1996, em uma área de pastagem natural localizada no município de Viçosa (MG). Foram utilizados novilhos canulados no esôfago, rúmen e abomaso, durante dois períodos experimentais em cada estação, e usados indicadores externos $\left(\mathrm{Cr}_{2} \mathrm{O}_{3}\right.$ e Eu) para estimativa do consumo e da taxa de passagem da digesta no rúmen. Foram determinados os fluxos de nitrogênio total e de nitrogênio bacteriano no abomaso, os carboidratos totais e estruturais digeridos no rúmen e os teores em nutrientes digeríveis totais. Estas variáveis também foram preditas a partir do modelo descrito no sistema Cornell, para validação de suas estimativas. Verificou-se que o modelo foi sensível às estimativas das taxas de passagem, superestimou (12,38\%) o fluxo de nitrogênio bacteriano no abomaso e subestimou (70,64\%) a disponibilidade ruminal dos carboidratos estruturais. O emprego da taxa de passagem de $0,02 \mathrm{~h}^{-1}$ no cálculo das estimativas resultou no aumento da superestimação do fluxo de $\mathrm{N}$ de origem bacteriana (28,66\%), em virtude da maior degradação dos carboidratos estruturais, cuja estimativa permaneceu subestimada em $21,55 \%$. A redução do consumo de matéria seca foi mais bem correlacionada aos teores de FDN indigerível que aos teores de FDN, devendo-se ressaltar que a capacidade diária de consumo desta fração foi de $0,6 \%$ do peso vivo e não diferiu entre estações.
\end{abstract}

Palavras-chave: digestão, modelos matemáticos, pastos tropicais, ruminantes

\section{Simulation of the Nutrient Dynamics in the Gastrointestinal Tract: Application and Validation of a Mathematical Model for Grazing Cattle}

\begin{abstract}
The objective of the present work was to validate the ruminal and post-ruminal nutrient dynamics and the ruminal microbial growth predictions, by using the equations of the Cornellsystem. The experiment was carried out during the rainy and dry seasons of the 1996 year, in a natural pasture area situated in the county of Viçosa (MG). Esophageally, ruminally and abomasally cannulated steers were used during two experimental periods within each season, and external markers $\left(\mathrm{Cr}_{2} \mathrm{O}_{3}\right.$ and Eu) were used to estimate the intake and the ruminal digesta passage rate. The total nitrogen and the bacterial nitrogen flows, total and structural carbohydrates digested in the rumen, and the total of digestible nutrients contents were determined. These variables were also predicted from the model described in the Cornell system to validate its estimates. It was verified that the model was sensitive to the passage rate estimates, overestimated (12.38\%) the bacterial nitrogen flow to the abomasum, and underestimated (70.64\%) the structural carbohydrates availability in the rumen. The correction based on $.02 \mathrm{~h}^{-1}$ passage rate in the estimates calculation resulted in an overestimation increase of the bacterial $\mathrm{N}$ flow ( $\left.28.66 \%\right)$ due to the greatest structural carbohydrate degradation, whose estimates remained underestimated in $21.55 \%$. The dry matter intake reduction was better correlated with the indigestible NDF than NDF contents itself, and it should be emphasized that the daily intake capacity of this fraction was $0.6 \%$ of the live weight and it did not differ between seasons.
\end{abstract}

Key Words: digestion, mathematical models, ruminants, tropical pastures

\section{Introdução}

A representação da essência de determinada realidade mediante a utilização de meios artificiais, com a finalidade de obter informações relativas a determinado evento ou conjunto de eventos que, isolado ou simultaneamente, podem ocorrer dentro dos limites que caracterizam o objeto de estudo, consiste no que se pode denominar de simulação de sistemas. Tal processo compreende o desenvolvimento e a aplicação de modelos para o estudo da dinâmica das relações existentes em determinado

\footnotetext{
${ }^{1}$ Parte da Tese de Doutorado do primeiro autor, financiada pelo CNPq.

2 Professor Adjunto, UEG, Anápolis, GO; Pesquisador, NASB/CCA/IMEP, Caixa Postal 21, cep: 75180-000, Silvânia, GO.

${ }^{3}$ Prof. Titular, DZO/UFV, Viçosa - MG.

${ }^{4}$ Prof. Adjunto, DNAP/IZ/UFRRJ, Seropédica RJ.

5 Professor Titular, DEQ/UFV.

${ }^{6}$ Pesquisador, convênio PROCABRA/DZO/UFV, Viçosa, MG.
} 
sistema; portanto, a operação de modelos físicos, matemáticos ou de ambos, para obtenção de predições relativas ao possível comportamento das variáveis no mundo real, é o resultado direto dos estudos de simulação (MERTENS, 1976).

Pode-se definir um modelo como uma representação simplificada, abstrata e idealizada de determinada realidade; qualquer tipo de modelo, por definição, deve basear-se em argumentações ordenadas, lógicas e justificáveis, pressupostas a partir do conhecimento científico existente sobre o assunto em questão. Um modelo matemático é uma equação, ou conjunto de equações, cuja resolução implica a predição de mudanças que podem ocorrer na realidade; é a conseqüência ou o resultado direto de empreendimentos analíticos para a abstração e definição do mundo real, em termos matemáticos precisos (SHANNON, 1975; MERTENS, 1976; e GRAYBEAL e POOCH, 1980).

O sistema Cornell (FOX et al., 1992; RUSSELL et al., 1992; SNIFFEN et al., 1992; e O'CONNOR et al. 1993) foi desenvolvido basicamente com o objetivo avaliar melhor as dietas dos bovinos, visando minimizar asperdas de nutrientes e buscar a maximização da eficiência de crescimento dos microrganismos do rúmen (RUSSELL, 1992; VAN SOEST, 1994). Nesse sistema, o submodelo relativo ao trato gastrintestinal é constituído de equações que, a partir de determinações com base em métodos químicos e biológicos, permitem estimar a dinâmica ruminal e pós-ruminal dos nutrientes dietéticos, o crescimento microbiano em nível de rúmen e, conseqüentemente, o aporte de energia e proteína metabolizáveis para o hospedeiro (RUSSELL et al., 1992; SNIFFEN et al., 1992). Torna-se imperativo, portanto, verificar a exatidão de tais estimativas para o aprimoramento desse modelo matemático, bem como dos modelos físicos (métodos biológicos) usados na obtenção das estimativas dos parâmetros do modelo, para que seja avaliada sua aplicabilidade sob várias condições de alimentação. A melhor maneira de verificar a aplicabilidade de determinado modelo consiste na comparação dos valores preditos com as estimativas obtidas no sistema real, ou seja, in vivo (KRISHNAMOORTHY et al., 1983; O'CONNOR et al., 1993).

O uso indiscriminado de estimativas obtidas sob diferentes circunstâncias pode dificultar a predição do valor nutritivo dos alimentos e do desempenho animal sob condições práticas de alimentação (VAN SOEST, 1994). Para evitar os ajustes de natureza subjetiva, os estudos que visam a determinação do valor nutritivo dos alimentos devem se basear em condições dietéticas próximas às que se deseja inferir, e, assim, tornar prático o uso de determinado conjunto de dados nos estudos de simulação, para avaliação e formulação de dietas para bovinos.

Estando os ruminantes domésticos no Brasil, principalmente os bovinos, submetidos a condições dietéticas nas quais as pastagens constituem importante fonte de nutrientes, a obtenção das estimativas da dinâmica ruminal e pós-ruminal dos mesmos e a verificação do valor nutritivo predito a partir de tais estimativas tornam-se necessidades prementes para o uso dos modernos sistemas de avaliação de alimentos e de determinação das exigências nutricionais para esses animais.

O objetivo do presente trabalho foi a validação das predições com base nas estimativas dos parâmetros da dinâmica ruminal e pós-ruminal dos nutrientes e do crescimento microbiano em nível de rúmen, utilizando as equações que compõem o submodelo relativo ao trato gastrintestinal do sistema Cornell.

\section{Material e Métodos}

O experimento foi realizado durante as estações chuvosa e seca do ano de 1996, em uma área de pastagem natural (cujas características foram descritas por VIEIRA et al., 2000a), localizada no município de Viçosa, Estado de Minas Gerais, Brasil. A altitude média local é de $651 \mathrm{~m}$ e as coordenadas geográficas são $20^{\circ} 45^{\prime}$ de latitude sul e $42^{\circ} 51^{\prime}$ de longitude oeste. De acordo com os dados da estação meteorológica da Universidade Federal de Viçosa, a média da temperatura do ar nos meses de dezembro (1995), janeiro e fevereiro de 1996 foi de $23,65^{\circ} \mathrm{C}$ e a média das máximas e mínimas de 28,91 e $18,39^{\circ} \mathrm{C}$, respectivamente; a umidade relativa média do ar nestes meses foi de $80,89 \%$ e a precipitação pluviométrica atingiu $499,9 \mathrm{~mm}$, tendo $68,45 \%$ deste total ocorrido durante o mês de dezembro de 1995 . Nos meses de julho, agosto e setembro de 1996, a temperatura média do ar foi de $17,92^{\circ} \mathrm{C}$, e a média das máximas e mínimas de 24,28 e $11,57^{\circ} \mathrm{C}$, respectivamente; nesses meses, a umidade relativa média do ar foi de $76,52 \%$ e a precipitação pluviométrica acumulada, de $79,4 \mathrm{~mm}$, tendo $85,77 \%$ deste total ocorrido durante o mês de setembro de 1996. O clima da região é classificado como Cwa, segundo a classificação de Köppen.

As amostras de extrusa (detalhes descritos por VIEIRA et al., 2000a), de digesta abomasal e de fezes foram obtidas de quatro novilhos, com peso vivo 
900

Rev. bras. zootec.

médio de $408 \mathrm{~kg}$, fistulados no esôfago, rúmen e abomaso, em dois períodos experimentais (12/01 a 27/01 e 30/01 a 16/02), durante a estação chuvosa (EC) do ano de 1996 e, três destes animais, com peso vivo médio de $416 \mathrm{~kg}$, em dois períodos experimentais (29/07 a 13/08 e 17/08 a 05/09), durante a estação seca (ES) desse ano.

Os animais receberam, via cânula ruminal, $5 \mathrm{~g}$ de óxido crômico $\left(\mathrm{Cr}_{2} \mathrm{O}_{3}\right)$ pela manhã (8 horas) e à tarde (17 h), durante todos os dias de cada período experimental, dentro das respectivas estações.

As amostras da digesta abomasal foram coletadas em intervalos de 28 horas, durante seis dias de coleta, em cada período experimental (CECAVA et al., 1990). Foram coletadas seis amostras por animal, e, à medida que estas eram coletadas, eram levadas imediatamente ao laboratório, para secagem em estufa ventilada a $55^{\circ} \mathrm{C}$, por 72 horas. Em seguida, as amostras pré-secas foram moídas, para atingirem granulometria de $1 \mathrm{~mm}$, sendo feita, posteriormente, uma amostra composta com base no peso seco para cada animal, nos respectivos períodos de coleta.

Aproximadamente $1,5 \mathrm{~L}$ de conteúdo ruminal ( $80 \%$ de fase líquida e $20 \%$ de fase sólida) de cada animal foi coletado, para determinar a relação entre o teor de nitrogênio em bases purínicas e o teor de nitrogênio total (N-RNA:N-total) na biomassa bacteriana, sendo o material ruminal imediatamente processado, para obtenção da biomassa, de acordo com os procedimentos descritos por CECAVA et al. (1990). Com este procedimento, foi obtida uma amostra composta por período experimental, a partir do conteúdo ruminal individual dos animais. A determinação do teor de nitrogênio em bases purínicas, tanto nas amostras de bactérias quanto na digesta abomasal, foi obtida por método colorimétrico, após a digestão da amostra em ácido perclórico e precipitação destas bases nitrogenadas, na presença de nitrato de prata (USHIDA et al., 1985; ZINN e OWENS, 1986).

O consumo de matéria seca (CMS) de cada animal, nos respectivos períodos dentro de cada estação, foi estimado por meio da expressão:

$$
\operatorname{CMS}\left(k g d^{-1}\right)=\frac{\operatorname{MSF}\left(k g d^{-1}\right)}{\mathrm{FI}}
$$

em que MSF é a produção de matéria seca fecal, estimada por $\mathrm{Cr}_{2} \mathrm{O}_{3}$ e FI, o fator de indigestibilidade da matéria seca do pasto, dado pelo quociente (100 Coeficiente de Digestibilidade da MS do pasto)/100, calculado com base no teor de fibra em detergente neutro indigerível $\left(\mathrm{FDN}_{\mathrm{I}}\right)$ como indicador, estimada após 96 horas de incubação in vitro (MERTENS, 1993; VAN SOEST, 1994). A digestibilidade da matéria seca originária do pasto consumido e o fluxo de matéria seca abomasal foram estimados individualmente para os animais, mediante a determinação do teor de $\mathrm{FDN}_{\mathrm{I}}$ in vitro, nas amostras de extrusa, abomaso e fezes. Os teores de cromo na matéria seca fecal e os de fibra em detergente neutro (FDN) na matéria seca da extrusa, na matéria seca abomasal e na matéria seca fecal foram determinados de acordo com os procedimentos descritos por WILLIAMS et al. (1962) e VAN SOEST et al. (1991). A determinação dos teores em diferentes compostos nitrogenados, carboidratos, lignina, extrato etéreo e matéria mineral foi obtida de acordo com os procedimentos descritos por VIEIRA et al. (2000a,b).

As taxas de passagem relativas às amostras de extrusa de cada animal foram estimadas utilizando-se o európio $(\mathrm{Eu})$ como indicador. $\mathrm{O}$ preparo do material marcado foi realizado de acordo com a metodologia descrita por ELLIS e BEEVER (1984), tendo sido usados $5 \mathrm{mg}$ de Eu por grama de fibra, que, por sua vez, foi preparada segundo a metodologia descrita por UDÉN et al. (1980). Os tempos para a coleta de fezes e a interpretação cinética dos perfis de excreção fecal do indicador seguiram os mesmos procedimentos empregados por VIEIRA et al. (1997).

A validação das predições relativas à dinâmica ruminal e pós-ruminal dos nutrientes foi realizada por meio da regressão dos valores observados sobre os valores preditos dos fluxos de nitrogênio total $\left(\mathrm{g} \mathrm{d}^{-1}\right)$, de nitrogênio de origem bacteriana no abomaso $\left(\mathrm{g} \mathrm{d}^{-1}\right)$, das digestibilidades ruminais dos carboidratos totais $\left(\mathrm{g} \mathrm{d}^{-1}\right)$ e dos carboidratos estruturais $\left(\mathrm{g} \mathrm{d}^{-1}\right)$.

As estimativas dos parâmetros das equações de regressão foram testadas contra as hipóteses $H_{0}^{(\mathrm{a})}: \beta_{0}=0$ e $H_{0}^{(\mathrm{b})}: \beta_{1}=1$, o que permitiu identificar se o modelo Cornell superestimava ou subestimava os valores preditos em relação aos valores observados. $\mathrm{O}$ vício das estimativas foi calculado multiplicandose por $100 \mathrm{o}$ coeficiente angular do modelo $Y=\beta_{1} X$, em que $\mathrm{Y}$ corresponde aos valores observados e $\mathrm{X}$ representa os valores preditos (O'CONNOR et al., 1993).

A variação dos valores observados para o consumo de matéria seca, a eficiência de síntese de compostos nitrogenados no rúmen, o fluxo de nitrogênio abomasal, o fluxo de nitrogênio bacteriano no abomaso, a quantidade de carboidratos totais digeridos no rúmen (CTDR) e o teor em nutrientes digeríveis totais (NDT), em função das estações e dos períodos dentro de estação, foi analisada de acordo com o modelo estatístico descrito por VIEIRA et al. (2000a). 


\section{Resultados e Discussão}

As estimativas médias das frações de compostos nitrogenados e dos carboidratos, bem como suas degradabilidades em nível de rúmen, podem ser obtidas a partir da Tabela 1 e das estimativas dos parâmetros relacionados à cinética de degradação das frações $\mathrm{B}_{2}$ e $B_{3}$ dos compostos nitrogenados e da fração $B_{2}$ da fibra em detergente neutro (VIEIRA et al., 2000a,b).

Exceto para o consumo de matéria seca (CMS) e o consumo diário de nitrogênio $(\mathrm{CN})$, as estimativas listadas na Tabela 2 foram medidas diretamente nos animais (valores observados) e preditas simulandose o modelo Cornell. O CMS reduziu significativamente entre as estações, passando de $10539 \mathrm{~g} \mathrm{~d}^{1}$ $\left(26 \mathrm{~g} \mathrm{~kg}^{-1} \mathrm{PV} \mathrm{d}^{-1}\right)$ na estação chuvosa para $7777 \mathrm{~g} \mathrm{~d}^{-1}$ $\left(19 \mathrm{~kg}^{-1} \mathrm{PV} \mathrm{d}^{-1}\right)$ na estação seca (Tabelas 2 e 3 ). Ocorreram reduções significativas entre estações (Tabelas 2 e 3) para o consumo total de nitrogênio (144 $\mathrm{g} \mathrm{d}^{-1}$ vs. $61 \mathrm{~g} \mathrm{~d}^{-1}$ ), o fluxo de nitrogênio total no abomaso (190 $\mathrm{g} \mathrm{d}^{-1}$ vs. $\left.100 \mathrm{~g} \mathrm{~d}^{-1}\right)$, o fluxo de nitrogênio de origem protéica no abomaso (113 $\left.\mathrm{g} \mathrm{d}^{-1} \mathrm{vs.} 72 \mathrm{~g} \mathrm{~d}^{-1}\right)$, o fluxo de nitrogênio de origem bacteriana mo abomaso (116 $\mathrm{g} \mathrm{d}^{-1}$ vs. $\left.76 \mathrm{~g} \mathrm{~d}^{-1}\right)$, a quantidade de carboidratos totais digeridos no rúmen (4513 $\mathrm{g} \mathrm{d}^{-1}$ vs. $\left.3126 \mathrm{~g} \mathrm{~d}^{-1}\right) \mathrm{e}$ os teores em nutrientesdigeríveis totais $\left(568 \mathrm{~g} \mathrm{~kg}^{-1} \mathrm{MS}\right.$ vs. $477 \mathrm{~g} \mathrm{~kg}^{-1} \mathrm{MS}$ ). Foi verificado aumento significativo no fluxo de nitrogênio insolúvel em detergente ácido no abomaso de $10 \mathrm{~g} \mathrm{~d}^{1}$ na EC para $13 \mathrm{~g} \mathrm{~d}^{1}$ na ES (Tabelas 2 e 3). Não foi detectado efeito de estação sobre o rendimento microbiano, cuja estimativa média foi de $25 \mathrm{~g} \mathrm{~N} \mathrm{~kg}^{-1} \mathrm{CTDR} \mathrm{d}^{-1}$ (Tabelas $2 \mathrm{e} 3$ ). Entre as variáveis analisadas, o teor de NDT apresentou elevado grau de precisão para as estimativas, enquanto a menor precisão foi verificada para as estimativas do fluxo de nitrogênio bacteriano no abomaso (Tabela 3).

A redução significativa do consumo de matéria seca entre estações pode ser explicada pelo aumento na proporção do resíduo indigerível da fibra em detergente neutro $\left(\mathrm{FDN}_{\mathrm{I}}\right)$, que está relacionado a maiores tempos de retenção da digesta no rúmen (VIEIRA et al., 1997). Embora a correlação negativa entre o CMS e os teores de $\mathrm{FDN}_{\mathrm{I}}$ não permita estabelecer uma relação entre causa e efeito $(\hat{\rho}=-0,6712 ; P=0,004)$, não houve diferença significativa para o efeito de estação sobre o consumo de FDN $_{\mathrm{I}}$ pelos animais $(\hat{F}<1 ; \mathrm{CV}=21,80 \%)$, cuja estimativa média foi de $2351 \mathrm{~g} \mathrm{~d}^{-1} \mathrm{ou} 6 \mathrm{~g} \mathrm{~kg}^{-1} \mathrm{PV} \mathrm{d}^{-1}$. VIEIRA et al. (1997) especularam que o resíduo indigerível da FDN poderia ser usado na predição do CMS em substituição à FDN propriamente dita, pelo fato de o resíduo indigerível, representado pela fração I(VIEIRA

\begin{tabular}{|c|c|c|c|c|}
\hline \multirow[b]{2}{*}{ Item } & \multicolumn{2}{|c|}{$\begin{array}{l}\text { Estação chuvosa } \\
\text { Rainy season }\end{array}$} & \multicolumn{2}{|c|}{$\begin{array}{c}\text { Estação seca } \\
\text { Dry season }\end{array}$} \\
\hline & $\begin{array}{l}\text { Período } 1 \\
\text { Period } 1\end{array}$ & $\begin{array}{l}\text { Período } 2 \\
\text { Period } 2\end{array}$ & $\begin{array}{l}\text { Período } 1 \\
\text { Period } 1\end{array}$ & $\begin{array}{l}\text { Período } 2 \\
\text { Period } 2\end{array}$ \\
\hline$\overline{\mathrm{FDN}^{1}}$ & 754 & 740 & 776 & 791 \\
\hline Lignina & 55 & 64 & 76 & 59 \\
\hline \multicolumn{5}{|l|}{ Lignin } \\
\hline FDNcp ${ }^{2}$ & 681 & 682 & 723 & 742 \\
\hline $\mathrm{CHOS}^{3}$ & 12 & 7 & 9 & 4 \\
\hline $\mathrm{PB}^{4}$ & 89 & 80 & 44 & 54 \\
\hline $\mathrm{PS}^{5}$ & 8 & 10 & 11 & 11 \\
\hline NNP6 & 5 & 6 & 4 & 7 \\
\hline $\mathrm{PIDN}^{7}$ & 67 & 51 & 25 & 30 \\
\hline PIDA $^{8}$ & 18 & 21 & 15 & 18 \\
\hline $\mathrm{EE}^{9}$ & 14 & 11 & 8 & 8 \\
\hline $\mathrm{MM}^{10}$ & 113 & 109 & 109 & 105 \\
\hline
\end{tabular}

1 Fibra em detergente neutro; ${ }^{2} \mathrm{FDN}$ corrigida para proteína e cinzas; ${ }^{3}$ carboidratos solúveis em água; ${ }^{4}$ proteína bruta; ${ }^{5}$ proteína solúvel; ${ }^{6}$ nitrogênio não-protéico (multiplicado por 6,25 ); ${ }^{7}$ proteína insolúvel em detergente neutro; ${ }^{8}$ proteína insolúvel em detergente ácido; ${ }^{9}$ extrato etéreo; ${ }^{3}$ matéria mineral.

1 Neutral detergent fiber; ${ }^{2}$ NDF corrected for protein and ash; ${ }^{3}$ water-soluble carbohydrates; ${ }^{4}$ crude protein; ${ }^{5}$ solubleprotein; ${ }^{6}$ non-protein nitrogen (multiplied by 6.25); ${ }^{7}$ neutral detergent insoluble protein; ${ }^{8}$ acid detergent insoluble protein; ${ }^{9}$ ether extract; ${ }^{10}$ ash. 
Tabela 2 - Estimativas da dinâmica dos nutrientes (valores observados), para os diferentes períodos dentro de cada estação

Table 2 - Estimates of the nutrient dynamics (observed values) for different periods within each season

\begin{tabular}{|c|c|c|c|c|}
\hline \multirow[b]{2}{*}{ Item } & \multicolumn{2}{|c|}{$\begin{array}{c}\text { Estação chuvosa } \\
\text { Wet season }\end{array}$} & \multicolumn{2}{|c|}{$\begin{array}{c}\text { Estação seca } \\
\text { Dry season }\end{array}$} \\
\hline & $\begin{array}{l}\text { Período } 1 \\
\text { Period } 1\end{array}$ & $\begin{array}{l}\text { Período } 2 \\
\text { Period } 2 \\
\end{array}$ & $\begin{array}{l}\text { Período } 1 \\
\text { Period } 1\end{array}$ & $\begin{array}{l}\text { Período } 2 \\
\text { Period } 2 \\
\end{array}$ \\
\hline $\begin{array}{l}\text { Consumo } \mathrm{MS}^{1} \\
\text { Dry matter intake }\end{array}$ & 11035 & 10042 & 7994 & 7560 \\
\hline $\begin{array}{l}\text { Consumo } \mathrm{N}^{1} \\
N \text { intake }\end{array}$ & 159 & 129 & 56 & 66 \\
\hline $\begin{array}{l}\text { Fluxo } \mathrm{N}^{1} \\
N \text { flow }^{l}\end{array}$ & 210 & 169 & 105 & 94 \\
\hline $\begin{array}{l}\text { Fluxo N protéico } \\
\text { Protein } N \text { flow }^{1}\end{array}$ & 126 & 100 & 75 & 68 \\
\hline $\begin{array}{l}\text { Fluxo } \mathrm{N} \text { bactérias } \\
\text { Bacterial } N \text { flow }^{1}\end{array}$ & 132 & 99 & 93 & 59 \\
\hline $\begin{array}{l}\text { Fluxo NIDA } \\
\text { ADIN flow }\end{array}$ & 10 & 10 & 15 & 11 \\
\hline $\begin{array}{l}\mathrm{CTDR}^{1,2} \\
\operatorname{TCDR}^{1,2}\end{array}$ & 4737 & 4289 & 3079 & 3173 \\
\hline $\begin{array}{l}\mathrm{NDT}^{3} \\
T D N^{3}\end{array}$ & 607 & 529 & 472 & 481 \\
\hline $\begin{array}{l}\text { Rendimento } \\
\text { Yield }\end{array}$ & 28 & 23 & 30 & 19 \\
\hline
\end{tabular}

Tabela 3 - Níveis descritivos dos testes (valores $P$ ) para os efeitos de estação e períodos dentro de estação chuvosa (P/EC) e seca (P/ES) sobre a dinâmica dos nutrientes (valores observados)

Table 3 - Descriptive levels of the tests ( $P$ values) applied to verify the effects of season and periods within rainy $(P / E C)$ and dry (P/ES) seasons on the nutrient dynamics (observed values)

\begin{tabular}{lcccc}
\hline Item & $\begin{array}{c}\text { Estação } \\
\text { Season }\end{array}$ & P/EC & P/ES & CV (\%) \\
\hline $\begin{array}{l}\text { Consumo MS } \\
\text { Dry matter intake }\end{array}$ & 0,013 & n.s. & n.s. & 18,44 \\
$\begin{array}{l}\text { Consumo N } \\
\text { intake }\end{array}$ & 0,000 & 0,101 & n.s. & 21,52 \\
$\begin{array}{l}\text { Fluxo N } \\
N \text { flow }\end{array}$ & 0,000 & 0,090 & n.s. & 20,51 \\
$\begin{array}{l}\text { Fluxo N protéico } \\
\text { Protein N flow }\end{array}$ & 0,004 & 0,112 & n.s. & 21,84 \\
$\begin{array}{l}\text { Fluxo N bactérias } \\
\text { Bacterial Nflow }\end{array}$ & 0,019 & 0,107 & 0,138 & 26,43 \\
$\begin{array}{l}\text { Fluxo NIDA } \\
\text { ADIN flow }\end{array}$ & 0,047 & n.s. & 0,076 & 19,56 \\
$\begin{array}{l}\text { CTDR } \\
\text { TCDR }\end{array}$ & 0,011 & n.s. & n.s. & 20,98 \\
NDT & 0,000 & 0,001 & n.s. & 4,46 \\
$\begin{array}{l}T D N \\
\text { Rendimento }\end{array}$ & n.s. & 0,151 & 0,006 & 15,81 \\
Yield & & & & \\
\hline
\end{tabular}

n.s., não-significativo, usado quando . .

n.s., non significative, used when . 
et al., 1999b), ter exercido maior efeito na repleção ruminal da FDN como um todo. O coeficiente de correlação entre o CMS e os teores de FDN nas amostras do pasto foi de $-0,5328(P=0,025)$, sendo detectada redução significativa do consumo de FDN entre as estações $(P=0,031 ; \mathrm{CV}=18,82 \%)$, o que significa dizer que o consumo de FDN não foi constante $\left(19 \mathrm{~g} \mathrm{~kg}^{-1} \mathrm{PV} \mathrm{d}^{-1}\right.$ contra $\left.15 \mathrm{~g} \mathrm{~kg}^{-1} \mathrm{PV} \mathrm{d}^{-1}\right)$ e dependeu da qualidade desse nutriente no pasto. No entanto, os teores de $\mathrm{N}$ da dieta durante a estação seca estiveram abaixo do intervalo crítico de 60 a $80 \mathrm{~g} \mathrm{~PB} \mathrm{~kg}^{-1}$ MS (VAN SOEST, 1994) e, aliado ao fato de que houve redução significativa na taxa de degradação da fração potencialmente degradável da FDN (VIEIRA et al., 1999b), ocorreu confundimento entre o teor de $\mathrm{N}$ da dieta e o efeito da fração indigerível da fibra; o menor teor de nitrogênio da dieta pode ter contribuído para potencializar o efeito de repleção ruminal total da FDN. MERTENS (1987) sugeriu que a capacidade de consumo de FDN era um valor fixo de $12 \mathrm{~g} \mathrm{~kg}^{-1} \mathrm{PV} \mathrm{d}^{-1}$; a capacidade de consumo de $\mathrm{FDN}_{\mathrm{I}}$ dos animais no presente estudo foi exatamente a metade deste valor, e sua estimativa apresentou a vantagem de não sofrer alteração em função da variação na fração potencialmente degradável da FDN.

A relação entre o nitrogênio contido nas bases purínicas (N-RNA) e o nitrogênio total (NT) contido nas amostras de bactérias foi, respectivamente, de 0,1527 e 0,1670 nos dois períodos da EC e 0,1243 e 0,1272 nos dois períodos da ES. Os teores de NT encontrados nas amostras de bactérias foram, para os quatro períodos experimentais, de 8,$24 ; 8,52 ; 4,58$; e $5,51 \%$ da matéria seca.

As bactérias contêm, geralmente, $50 \%$ de proteína, $23 \%$ de ácidos nucléicos, 9\% de lipídeos e 18\% de carboidratos, mas esta composição pode ser alterada significativamente em face das condições limitantes em determinados nutrientes no meio, principalmente o $\mathrm{N}$; as alterações mais dramáticas ocorrem no conteúdo em carboidratos (NOCEK e RUSSELL, 1988). Não é surpreendente, portanto, que os dados de rendimento microbiano, expressos em massa de células, sejam extremamente variáveis e atinjam valores literalmente absurdos. As estimativas de rendimento, no entanto, apresentam menor variação, se expressas com base no teor de $\mathrm{N}$ bacteriano, em vez do peso seco de células (NOCEK e RUSSELL, 1988). Pressupõe-se, para o sistema Cornell, que o teor de nitrogênio em ácidos nucléicos represente $15 \%$ do nitrogênio total contido na matéria seca bacteriana, que, por sua vez, deve conter, aproximadamente, $10 \%$ de $\mathrm{N}$ total (RUSSELL et al., 1992; VAN SOEST, 1994).

As estimativas médias para as taxas de passagem da digesta foram, respectivamente, de $0,059 \mathrm{~h}^{1} \mathrm{e}$ $0,054 h^{-1}$, para os dois períodos da EC, e $0,024 \mathrm{~h}^{-1} \mathrm{e}$ $0,026 h^{-1}$ para os dois períodos da ES. Estes valores foram empregados no cálculo da degradabilidade ruminal de carboidratos estruturais e das frações $B_{2}$ e $\mathrm{B}_{3}$ dos compostos nitrogenados. A simulação do modelo a partir das taxas de passagem observadas, permitiu ilustrar a menor disponibilidade em nutrientes digeríveis totais (NDT) e proteína metabolizável (PM) para os animais durante a estação seca, embora a diferença nos teores preditos de NDT entre as estações não tenha sido muito elevada (Tabela 4), quando comparada à verificada para os valores observados (Tabela 2).

A quantidade de nitrogênio amoniacal ruminal (NAR, Tabela 4) é estimada pelo somatório do nitrogênio originário da reciclagem endógena, do nitrogênio dietético de origem protéica degradado no rúmen e do nitrogênio não-protéico (NNP) dietético, descontando-se o somatório entre o nitrogênio retido nos peptídeos utilizados pelas bactérias que degradam os carboidratos não-estruturais, o nitrogênio amoniacal retido por estas bactérias e o nitrogênio amoniacal retido pelas bactérias que degradam os carboidratos estruturais (RUSSELL et al., 1992). Tomando como referência as estimativas baseadas nas taxas de degradação e de passagem, houve excesso de NAR no primeiro período da estação chuvosa, sincronismo no segundo período da mesma estação e déficit de nitrogênio em ambos os períodos da estação seca (Tabela 4). O déficit de nitrogênio predito pelo modelo é uma condição verificada na realidade, durante a estação seca, pois o fluxo de $76 \mathrm{~g} \mathrm{~d}^{-1}$ de nitrogênio bacteriano no abomaso foi maior que o consumo de $61 \mathrm{~g} \mathrm{~d}^{-1} \mathrm{de}$ $\mathrm{N}$ total (Tabela 2).

A disponibilidade de NAR é fator limitante ao crescimento microbiano também na estação chuvosa, se for considerada a taxa de passagem de $0,02 \mathrm{~h}^{-1}$ utilizada no AFRC (1993). Com base nestas estimativas, haveria sincronia entre carboidratos e proteínas no primeiro período da estação chuvosa e déficit de nitrogênio nas demais condições do presente estudo (Tabela 4). Esta carência de nitrogênio se deve ao fato de o rendimento microbiano ser basicamente predito a partir do somatório dos carboidratos (estruturais e não-estruturais) digeridos no rúmen (RUSSELL et al., 1992). O fornecimento de fontes protéicas de lenta degradação ruminal pode ser uma 
Tabela 4 - Valores preditos para os teores em nutrientes digeríveis totais (NDT, $\mathrm{g} \mathrm{kg}^{-1} \mathrm{MS}$ ), em proteína metabolizável ( $\mathrm{PM}, \mathrm{g} \mathrm{kg}^{-1} \mathrm{MS}$ ) e da disponibilidade de nitrogênio amoniacal ruminal (NAR, $\mathrm{g} \mathrm{d}^{-1}$ )

Table 4 - Predicted values for the contents in total of digestible nutrients (TDN, $\mathrm{kg}^{-1} \mathrm{DM}$ ), in metabolizable protein (MP, $\left.\mathrm{g} \mathrm{kg}^{-1} \mathrm{DM}\right)$, and for ruminal ammonia nitrogen availability (RAN, $\mathrm{g} \mathrm{d}^{-1}$ )

\begin{tabular}{|c|c|c|c|c|}
\hline \multirow[b]{2}{*}{ Item } & \multicolumn{2}{|c|}{$\begin{array}{c}\text { Estação chuvosa } \\
\text { Rainy season }\end{array}$} & \multicolumn{2}{|c|}{$\begin{array}{c}\text { Estação seca } \\
\text { Dry season }\end{array}$} \\
\hline & $\begin{array}{l}\text { Período } 1 \\
\text { Period } 1\end{array}$ & $\begin{array}{l}\text { Período } 2 \\
\text { Period } 2\end{array}$ & $\begin{array}{l}\text { Período } 1 \\
\text { Period } 1\end{array}$ & $\begin{array}{c}\text { Período } 2 \\
\text { Period } 2 \\
\end{array}$ \\
\hline $\mathrm{NDT}^{1}$ & 464 & 452 & 440 & 435 \\
\hline $\begin{array}{l}\mathrm{PM}^{1} \\
M P^{1}\end{array}$ & 62 & 63 & 50 & 49 \\
\hline $\begin{array}{l}\text { NAR }^{1} \\
\text { RAN }^{1}\end{array}$ & 20 & -2 & -26 & -10 \\
\hline $\begin{array}{l}\mathrm{NDT}^{2} \\
T D N^{2}\end{array}$ & 572 & 540 & 453 & 456 \\
\hline $\begin{array}{l}\mathrm{PM}^{2} \\
M P^{2}\end{array}$ & 68 & 69 & 52 & 51 \\
\hline $\begin{array}{l}\mathrm{NAR}^{2} \\
R A N^{2}\end{array}$ & -3 & -23 & -29 & -14 \\
\hline
\end{tabular}

alternativa para obtenção da sincronização entre a degradação dos carboidratos e a disponibilização de nitrogênio, principalmente para as bactérias que degradam os carboidratos estruturais, uma vez que estes constituem a principal fonte de energia nas condições dietéticas predominantes no ensaio em questão (VIEIRA et al., 2000a,b).

Os valores preditos para os fluxos de $\mathrm{N}$ total e de $\mathrm{N}$ de origem bacteriana no abomaso, para os carboidratos totais e os carboidratos estruturais digeridos no rúmen (Tabela 4), foram obtidos mediante a simulação do modelo com as estimativas observadas para as taxas de passagem da digesta, em cada período dentro das respectivas estações, bem como a partir da taxa de passagem descrita no AFRC (1993) para o plano de nutrição equivalente à manutenção dos animais $\left(0,02 \mathrm{~h}^{-1}\right)$, para os diferentes períodos em ambas as estações.

Considerando-se o modelo completo $\left(Y=\beta_{0}+\beta_{1} X\right)$ para a regressão dos valores observados sobre os preditos, pode-se notar, após a análise da Tabela 5, que as estimativas do intercepto e do coeficiente angular para os fluxos de $\mathrm{N}$ total e de $\mathrm{N}$ de origem bacteriana no abomaso, não diferiram dos valores paramétricos esperados de zero e um, embora o teste para o intercepto seja menos sensível, por causa da extrapolação, que o teste aplicado às estimativas do coeficiente de regressão. Para as variáveis em questão, a simulação do sistema Cornell resultou em predições que superestimaram, em menor grau, os fluxos de $\mathrm{N}$ total e de $\mathrm{N}$ de origem bacteriana no abomaso (Tabela 5). RUSSELL et al. (1992) fizeram menção a respeito das baixas estimativas observadas para o fluxo de $\mathrm{N}$ de origem bacteriana no abomaso de novilhos, o que implicava a superestimação desta variável, quando os valores observados eram comparados aos valores preditos ao simularem o modelo. Nos diagramas de dispersão confeccionados para estas variáveis, apresentados na Figura 1(a) e (b), pode-se notar que a maior proporção dos pontos se encontra abaixo da reta de equação $Y=X$, o que permite ilustrar a superestimação dos valores preditos pelo modelo.

O contrário pode ser dito em relação aos carboidratos totais e carboidratos estruturais digeridos no rúmen (Tabela 5). Apesar de não ter sido observada diferença entre as estimativas do intercepto e o valor paramétrico zero, as estimativas do coeficiente de regressão para ambas as variáveis foram significativamente maiores que um (Tabela 5). Tal fato permitiu identificar a subestimação da degradabilidade ruminal destes compostos, que, por sua vez, pode ser o resultado direto de dois fatores. $\mathrm{O}$ primeiro pode estar relacionado a falhas na obtenção das estimativas dos parâmetros da cinética de degradação in vitro destes compostos, particularmente dos carboidratos estruturais; o segundo e, mais provável, está relacionado a falhas na obtenção das estimativas dos parâmetros da cinética de trânsito 
das partículas da extrusa no rúmen. Pode-se notar, analisando a Figura 1(c e d), que a maior proporção dos pontos se encontra acima da reta de equação $\mathrm{Y}=\mathrm{X}$, o que indica a subestimação do modelo usado por VIEIRA et al. (2000b), no que se refere à degradabilidade ruminal dos carboidratos, particularmente os estruturais.

A simulação do modelo, empregando-se a taxa de passagem de $0,02 \mathrm{~h}^{-1}$, resultou em sensíveis alterações no comportamento dos valores preditos em relação aos valores observados, a começar pelo aumento do vício para as predições dos fluxos de $\mathrm{N}$ total e de $\mathrm{N}$ de origem bacteriana no abomaso (Tabela 5).
Contudo, as estimativas dos coeficientes de regressão para o fluxos de $\mathrm{N}$ total e de $\mathrm{N}$ bacteriano no abomaso não foram significativamente diferentes de um. Considerando-se o ajuste do modelo reduzido $\left(\mathrm{Y}=\beta_{1} \mathrm{X}\right)$, o vício das estimativas praticamente dobrou quando foi empregada a taxa de passagem do AFRC (1993); este efeito se deve principalmente à maior superestimação do fluxo de $\mathrm{N}$ de origem bacteriana (Tabela 5). Com a maior degradabilidade ruminal de carboidratos, o crescimento microbiano predito, principalmente dos microrganismos que utilizam os carboidratos estruturais, é demasiadamente elevado, o que explica o déficit de nitrogênio amoniacal ruminal
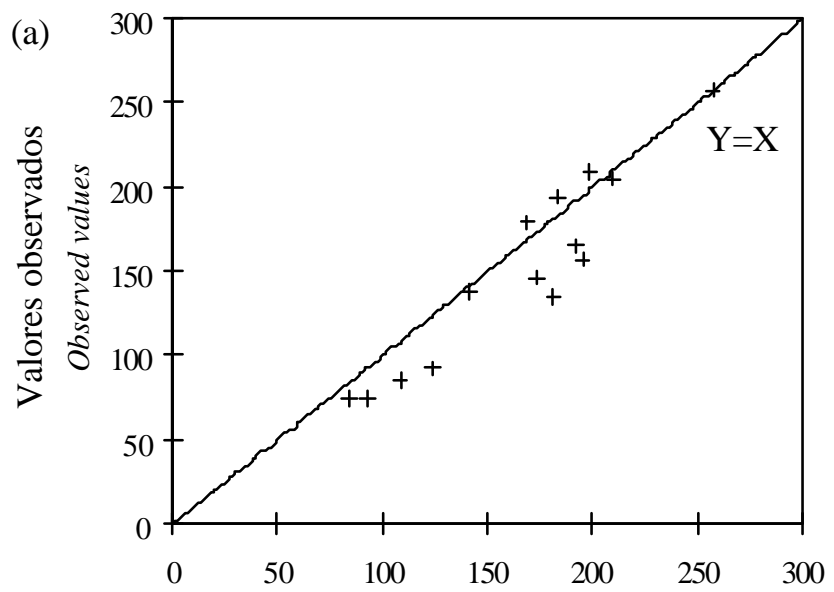

Valores preditos

Predicted values
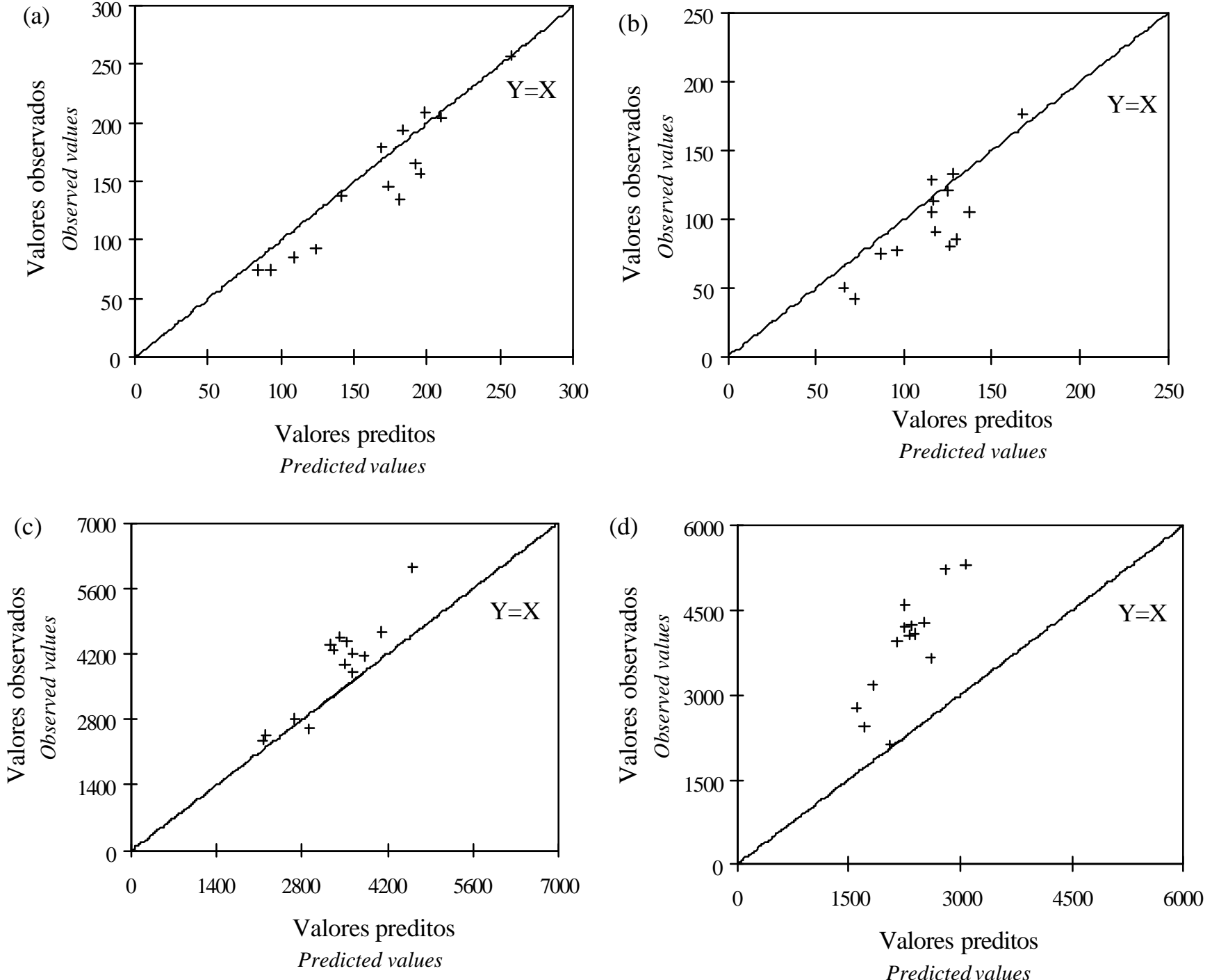

Figura 1 - Relação entre os valores observados e os preditos para o fluxo de $\mathrm{N}$ total no abomaso (a); fluxo de $\mathrm{N}$ de origem bacteriana no abomaso (b); e as quantidades de carboidratos totais (c) e carboidratos estruturais (d) digeridos no rúmen, considerando as estimativas observadas para as taxas de passagem em cada período, dentro das respectivas estações.

Figure 1 - Relation between observed and predicted values fortotal $N$ flow to the abomasum (a); bacterial nitrogen flow to the abomasum (b); quantities of total (c) and structural carbohydrates (d) digested in the rumen, by considering the observed passage rate estimates of each period, within the respective seasons. 
Tabela 5 - Estimativas dos parâmetros relativos à regressão dos valores observados sobre os preditos considerando o modelo completo $\left(Y=\beta_{0}+\beta_{1} X\right)$ e o modelo reduzido $\left(Y=\beta_{1} X\right)$

Table 5 - Parameters estimates related to the regression of the observed on the predicted values by considering the full $\left(Y=\beta_{0}+\beta_{1} X\right)$ and the reduced $\left(Y=\beta_{1} X\right)$ models

\begin{tabular}{|c|c|c|c|c|}
\hline \multirow[b]{2}{*}{ Item } & \multicolumn{2}{|c|}{$\begin{array}{l}\text { Modelo completo } \\
\text { Full model }\end{array}$} & \multicolumn{2}{|c|}{$\begin{array}{l}\text { Modelo reduzido } \\
\text { Reduced model }\end{array}$} \\
\hline & $\beta_{0}$ & $\beta_{1}$ & $\beta_{1}$ & $\begin{array}{c}\text { Vício }\left(\beta_{1}=1\right) \\
\text { Bias }\end{array}$ \\
\hline $\begin{array}{l}\text { Fluxo } \mathrm{N}^{1} \\
N \text { flow }^{1}\end{array}$ & $-26,69$ & 1,08 & 0,93 & $-7,30$ \\
\hline 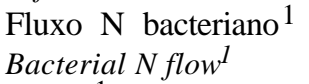 & $-30,05$ & 1,13 & 0,88 & $-12,38$ \\
\hline $\begin{array}{l}\mathrm{CTDR}^{1} \\
T C D R^{l}\end{array}$ & $-774,13$ & $1,40^{*}$ & 1,18 & 18,06 \\
\hline $\begin{array}{l}\mathrm{CEDR}^{1} \\
\text { SCDR }^{l}\end{array}$ & $-576,60$ & $1,95^{*}$ & 1,71 & 70,64 \\
\hline $\begin{array}{l}\text { Fluxo } N^{2} \\
N \text { flow }^{2}\end{array}$ & $-15,35$ & 0,93 & 0,85 & $-15,05$ \\
\hline $\begin{array}{l}\text { Fluxo } \mathrm{N} \text { bacteriano } \\
{\text { Bacterial } N \text { flow }^{2}}^{2}\end{array}$ & 1,14 & $0,71 *$ & 0,71 & $-28,66$ \\
\hline $\begin{array}{l}\mathrm{CTDR}^{2} \\
T C D R^{2}\end{array}$ & 443,43 & $0,83 *$ & 0,93 & $-7,30$ \\
\hline $\begin{array}{l}\mathrm{CEDR}^{2} \\
S C D R^{2}\end{array}$ & 946,46 & 0,93 & 1,22 & 21,55 \\
\hline
\end{tabular}

\footnotetext{
1 Com base nas taxas de passagem da extrusa em cada período dentro de estação.

2 Com base na taxa de passagem de $0,02 \mathrm{~h}^{-1}$ (AFRC, 1993); ${ }^{*} \mathrm{P}<0,05$ para as hipóteses $H_{0}^{(\mathrm{a})}: \beta_{0}=0$ e $H_{0}^{(\mathrm{b})}: \beta_{1}=1$.

1 Based on passage rates of each period within season.

2 Based on passage rate of $.02 h^{-1}$ (AFRC, 1993); ${ }^{*} P<.05$ for the hypothesis $H_{0}{ }^{(a)}: \beta_{0}=0$ and $H_{0}{ }^{(b)}: \beta_{1}=1$.
}

em ambas estações, quando se aplica a correção da taxa de passagem (Tabela 4). Comparando a Figura 1 (a e b) com a Figura 2 (a e b), pode-se observar o distanciamento dos pontos em relação à reta $\mathrm{Y}=\mathrm{X}$ após a correção da taxa de passagem, o que representa o aumento da superestimação do crescimento microbiano em nível de rúmen. No sistema Cornell, o rendimento microbiano é estimado a partir do valor constante de $40 \mathrm{~g}$ de $\mathrm{N}$ por $\mathrm{kg}$ de carboidratos (estruturais e não-estruturais) digeridos no rúmen (RUSSELL et al., 1992); estes valores apresentam boa acurácia para elevados fluxos de matéria seca no abomaso, que, por sua vez, são decorrentes de planos de nutrição superiores aos do presente estudo. Entretanto, quando se trata de baixos níveis de consumo, como mencionado anteriormente, são preditos valores superestimados para o fluxo de $\mathrm{N}$ bacteriano no abomaso.

$\mathrm{O}$ rendimento microbiano pode ser corrigido para o plano de nutrição (AFRC, 1993). O aumento neste último implica maiores rendimentos, principalmente pela redução da proporção de energia gasta com a manutenção dos microrganismos (RUSSELL e STROBEL, 1993). É possível que uma correção desta natureza resulte em predições mais exatas para o crescimento microbiano verificado em animais a pasto.

A correção para a taxa de passagem resultou em menores vícios para a degradabilidade ruminal dos carboidratos, principalmente aqueles pertencentes à parede celular vegetal (Tabela 5). Considerando-se o modelo de regressão completo, não foi rejeitada a hipótese $H_{0}^{(\mathrm{b})}: \beta_{1}=1$ para a degradabilidade ruminal dos carboidratos estruturais (Tabela 5). Os valores preditos para a degradabilidade ruminal da fibra foram mais sensíveis à correção efetuada na taxa de passagem durante a estação chuvosa, fato que pode ser observado analisando-se os diagramas das Figuras 1 (d) e 2 (d); o mesmo não ocorreu para a degradabilidade ruminal durante a estação seca. Contudo, ainda que corrigidos os valores preditos resultantes da simulação do modelo, as degradabilidades ruminais dos carboidratos estruturais permaneceram subestimadas, o que pode ser ilustrado pela proporção dos pontos que se encontram acima da reta de equação $\mathrm{Y}=\mathrm{X}$ (Figura $2 \mathrm{~d}$ ).

HUHTANEN et al. (1995) encontraram dois problemas para a estimação da degradabilidade ruminal da fibra (FDN), a partir de modelos matemáticos: subestimação das taxas de degradação in situ e do tempo médio de retenção das partículas no rúmen; entre eles, foi verificada maior sensibilidade para a taxa de degradação, uma vez que a utilização de modelos adequados à descrição dos perfis de 
VIEIRA et al.
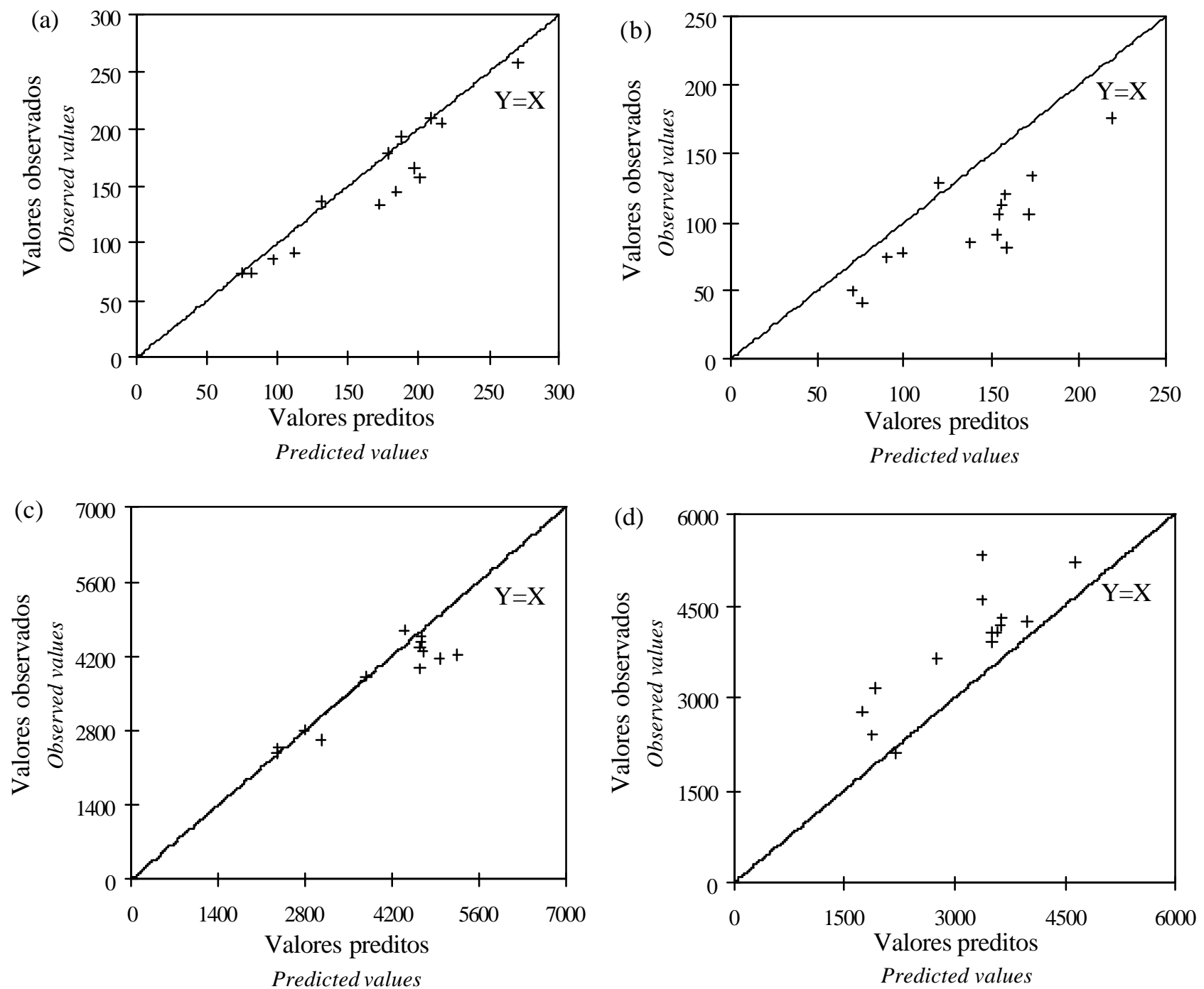

Figura 2 - Relação entre os valores observados e os preditos para o fluxo de $\mathrm{N}$ total no abomaso (a); fluxo de $\mathrm{N}$ de origem bacteriana no abomaso (b); e as quantidades de carboidratos totais (c) e carboidratos estruturais (d) digeridos no rúmen, considerando a taxa de passagem do AFRC (1993) de 0,02 $\mathrm{h}^{-1}$.

Figure 2 - Relation between observed and predicted values for total $N$ flow to the abomasum (a); bacterial nitrogen flow to the abomasum (b); quantities of total (c) and structural carbohydrates (d) digested in the rumen, by considering the AFRC (1993) passage rate of $0.02 h^{-1}$.

excreção fecal do indicador externo $(\mathrm{Cr}$ ou $\mathrm{Yb})$ promovia substancial redução no vício das estimativas de degradabilidade da fibra. Contudo, a grande sensibilidade do modelo utilizado no presente estudo (Eq. (7), VIEIRA et al., 2000b), em relação à correção para a estimativa da taxa de passagem, é indicativo de que cuidados devem ser tomados na obtenção destes valores. COMBS et al. (1992) avaliaram o itérbio $(\mathrm{Yb})$ e o cério $(\mathrm{Ce})$ como indicadores complexados à fibra e verificaram que ocorria substancial migração dos elementos tanto para partículas mais finas da digesta como para os microrganismos, o que acarretou em maiores taxas de passagem.
MOORE et al. (1992) verificaram que os elementos de terras raras apresentaram maiores taxas de passagem que o cromo $(\mathrm{Cr})$ complexado à fibra. Esses autores concluíram que os elementos de terras raras não devem ser utilizados para a determinação da taxa de passagem, quando os objetivos do estudo incluírem a obtenção de estimativas mais exatas deste parâmetro. É possível também que as elevadas taxas de passagem observadas durante a estação chuvosa no presente estudo tenham sido da maior digestibilidade da fibra da extrusa, o que resultou em maior descomplexação do indicador (UDÉN et al., 1980; OWENS e HANSON, 1992). 


\section{Conclusões}

A simulação do sistema Cornell, com base nas estimativas obtidas a partir de modelos físicos (métodos biológicos) e matemáticos, resultou na superestimação do fluxo de nitrogênio de origem microbiana no abomaso e subestimação da digestão ruminal dos carboidratos estruturais; o primeiro foi acentuado pela grande sensibilidade do modelo em relação à correção para as estimativas das taxas de passagem. Tal fato implica a necessidade de aperfeiçoamento dos métodos biológicos para a obtenção das estimativas dos parâmetros relativos à cinética de degradação da fibra e, principalmente, para a obtenção das estimativas das taxas de passagem das partículas originárias da forragem ou do pasto consumido pelos animais.

A redução do consumo de matéria seca entre estações deve-se à redução do consumo de FDN, cujo efeito de repleção ruminal é potencializado pela escassez de nitrogênio do pasto natural, durante a estação seca. A determinação da função do resíduo indigerível da FDN sobre a redução do consumo de matéria seca precisa ser melhor investigada, para que seja usada na predição do comportamento desta variável.

\section{Agradecimento}

Ao Conselho Nacional de Desenvolvimento Científico e Tecnológico (CNPq), pelas bolsas de estudo e pelo suporte financeiro ao projeto.

\section{Referências Bibliográficas}

AGRICULTURAL AND FOOD RESEARCH COUNCIL AFRC. 1993. Energy and protein requirements of ruminants. Cambridge: Cambridge University Press. 159p.

CECAVA, J.M., MERCHEN, N.R., GAY, L.C. et al. 1990. Composition of ruminal bacteria harvested from steers as influenced by dietary energy level, feeding frequency, and isolation technique. J. Dairy Sci., 73(9):2480-2488.

COMBS, D.K., SHAVER, R.D., SATTER, L.D. 1992. Retention of rare earths by hay particles following incubation in fresh or autoclaved rumen fluid. J. Dairy Sci., 75(1):132-139.

ELLIS, W.C., BEEVER, K.C. 1984. Methods of binding rare earths to specific feed particles. In: KENNEDY, C.P.M. (Ed.) Techniques in particle size analysis of feed and digesta in ruminants. Alberta: Canadian Society of Animal Production. p.154-165.

FOX, D.G., SNIFFEN, C.J., O'CONNOR, J.D. et al. 1992. A net carbohydrate and protein system for evaluating cattle diets: III. Cattle requirements and diet adequacy. J. Anim. Sci., 70(12):3578-3596.
GRAYBEAL, W.J., POOCH, U.W. 1980. Simulation:principles and methods. Cambridge: Winthrop Publishers, Inc. 249p.

HUHTANEN, P., JAAKKOLA, S., KUKKONEN, U. 1995. Ruminal plant cell wall digestibility estimated from digestion and passage kinetics utilizing mathematical models. Anim. Feed Sci. Technol., 52:159-173.

KRISHNAMOORTHY, U., SNIFFEN, C.J., STERN, M.D. et al. 1983. Evaluation of a mathematical model of rumen digestion and an in vitro simulation of rumen proteolysis to estimate the rumen-undegraded nitrogen content of feedstuffs. Br. J. Nutr., 50(3):555-568.

MERTENS, D.R. 1976. Principles of modeling and simulation in teaching and research. J. Dairy Sci., 60(7):1176-1186.

MERTENS, D.R. 1987. Predicting intake and digestibility using mathematical models of ruminal function. J. Anim. Sci., 64(6): 1548-1558.

MERTENS, D.R. 1993. Rate and extent of digestion. In: FORBES, J.M., FRANCE, J. (Eds.) Quantitative aspects of ruminant digestion and metabolism. Cambridge: Cambridge University Press. p.13-51.

MOORE, J.A., POND, K.R., POORE, M.H. et al. 1992. Influence of model and marker on digesta kinetic estimates for sheep. J. Anim. Sci., 70(12):3528-3540.

NOCEK, J.E., RUSSELL, J.B. 1988. Protein and energy as an integrated system. Relationship of ruminal protein and carbohydrate availability to microbial synthesis and milk production. J. Dairy Sci., 71(8):2070-2107.

O'CONNOR, J.D., SNIFFEN, C.J. FOX, D.G. et al. 1993. A net carbohydrate and protein system for evaluating cattle diets: IV. Predicting amino acid adequacy.J.Anim. Sci., 71(5):1298-1311.

OWENS, F.N., HANSON, C.F. 1992. External and internal markers for appraising site and extent of digestion in ruminants. J. Dairy Sci., 71(9):2605-2617.

RUSSELL,J.B. 1992. Minimizing ruminantnitrogenlosses.In:REUNIÃO ANUAL DA SOCIEDADE BRASILEIRA DE ZOOTECNIA/ SIMPÓSIO INTERNACIONAL DE NUTRIÇÃO DE RUMINANTES, 29, 1992, Lavras. Anais... Lavras: UFLA, 1992, p.47-64.

RUSSELL, J.B., O'CONNOR, J.D., FOX, D.G. et al.1992. A net carbohydrate and protein system for evaluating cattle diets: I. Ruminal fermentation. J. Anim. Sci., 70(12):3551-3561.

RUSSELL, J.B., STROBEL, H.J. 1993. Microbial Energetics. In: FORBES, J.M., FRANCE, J. (Ed.) Quantitative aspects of ruminant digestion and metabolism. Cambridge: Cambridge University Press. p.165-186.

SHANNON, R.E. 1975. Systems simulation: the art and science. Englewood Cliffs: Prentice Hall, Inc. 387p.

SNIFFEN, C.J., O'CONNOR, J.D., VAN SOEST, P.J. et al. 1992. A net carbohydrate and protein system for evaluating cattle diets: II. Carbohydrate and protein availability. J. Anim. Sci., 70(12):3562-3577.

UDÉN, P., COLUCCI, P.E., VAN SOEST, P.J. 1980. Investigation of chromium, cerium and cobalt as markers in digesta. Rate of passage studies. J. Sci. Food Agric., 31(3):625-632.

USHIDA, K., LASSALAS, B., JOUANY, J.P. 1985. Determinations of assay parameters of RNA analysis in bacterial and duodenal samples by spectrophotometry. Influence of sample treatment and preservation. Reprod. Nutr. Dévelop., 25:1037-1046.

VAN SOEST, P.J., ROBERTSON, J.B., LEWIS, B.A. 1991. Methods for dietary fiber, neutral detergent fiber, and nonstarch polyssacharides in relation to animal nutrition. J. Dairy Sci., 74(10):3583-3597. 
VAN SOEST, P.J. 1994. Nutritional ecology of the ruminant. 2.ed. Ithaca: Cornell University Press. 476p.

VIEIRA, R.A.M., PEREIRA, J.C., MALAFAIA, P.A.M. et al. 1997. The influence of elephant-grass (Pennisetumpurpureum Schum., Mineiro variety) growth on the nutrient kinetics in the rumen. Anim. Feed Sci. Technol., 67:151-161.

VIEIRA, R.A.M., PEREIRA, J.C. MALAFAIA, P.A.M. 2000a. Fracionamento e cinética de degradação in vitro dos compostos nitrogenados da extrusa de bovinos a pasto. Rev. bras. zootec., 29(3):880-888.

VIEIRA, R.A.M., PEREIRA, J.C., MALAFAIA, P.A.M. $2000 \mathrm{~b}$. Fracionamento dos carboidratos e cinética de degradação in vitro da fibra em detergente neutro da extrusa de bovinos a pasto. Rev. bras. zootec., 29(3):889-897.
WILLIAMS, C.H., DAVID, D.J., IISMAA, D. 1962. The determination of chromic oxide in faeces samples by atomic absorption spectrophotometry. J. Agric. Sci., 59(2):381-385.

ZINN, R.A., OWENS, F.N. 1986. A rapid procedure for purine measurement and its use for estimating net ruminal protein synthesis. Can. J. Anim. Sci., 66:157-166.

Recebido em: 09/09/98

Aceito em: 25/10/99 